\title{
ANALISIS PERILAKU ISLAMI TERHADAP NIAT BELI KOSMETIK HALAL MELALUI SIKAP KONSUMEN
}

\author{
Lisa Adriani \\ Fakultas Ekonomi Universitas Andalas, Indonesia \\ lisa19adriani@gmail.com \\ Ma'ruf \\ Fakultas Ekonomi Universitas Andalas, Indonesia \\ maruf@eb.unand.ac.id
}

\begin{abstract}
ABSTRAK
Tren di masyarakat Indonesia saat ini, yaitu tren hijrah. Masyarakat mengubah gaya hidup menjadi lebih sadar dan peduli dengan kehalalan suatu produk. Standar halal berkembang dari produk makanan-minuman, kini mencakup produk jasa dan gaya hidup (kosmetik halal). Salah satu kosmetik halal yang dijual di Indonesia yaitu Kosmetik Merek Make Over. Make Over telah terdaftar di Majelis Ulama Indonesia sebagai kosmetik halal. Tujuan penelitian adalah menganalisis pengaruh langsung antara variabel agama islam, pengetahuan halal, gaya hidup halal terhadap variabel niat beli dan pengaruh tidak langsung yang dimediasi oleh variabel sikap. Teknik pengambilan sampel yaitu purposive sampling sebanyak 185 responden. Teknik analisis data yaitu analisis kuantitatif dengan alat analisis menggunakan SMART PLS 3. Hasil analisis menunjukkan pengaruh positif signifikan antara variabel agama islam, pengetahuan halal, gaya hidup halal terhadap variabel niat beli secara langsung dan terdapat hubungan tidak langsung melalui variabel sikap dengan mediasi parsial. Sehingga pemasar perlu memperhatikan, mendukung prinsip halal dan open minded terhadap perubahan.
\end{abstract}

Kata kunci: Agama, Gaya Hidup, Halal, Indonesia, Islam, Kosmetik, Make Over, Niat Beli, Pengetahuan, Sikap

\section{ABSTRACT}

The current trend in Indonesian society is the hijrah trend. People change lifestyles to become more aware and concerned with the halal of a product. Halal standard developed from food-beverage products, now it develops service and lifestyle products (halal cosmetics). One of the halal cosmetics sold in Indonesia is the Make Over Cosmetics Brand. Make Over has been registered in the Indonesian Ulema Council as halal cosmetics. The purpose of this research is to analyze directly between the variables of Islamic religion, halal knowledge, halal lifestyle to the purchase intention variable and the indirect effect mediated by the attitude variable. The sampling technique is purposive sampling of 185 respondents. The data analysis technique is quantitative analysis using SMART PLS 3. The results of the analysis show a significant positive effect between Islamic religious variables, halal knowledge, halal lifestyle on direct purchase intention variables and indirectly related through influence variables with partial mediation. Need to be considered, supporting the principle of halal and open-minded to change.

Keywords: Religiosity, Lifestyle, Halal, Indonesia, Islam, Cosmetic, Make Over, Purchase Intention, Knowledge, Attitude 


\section{PENDAHULUAN}

Religiusitas mempengaruhi orientasi konsumen mengenai pola konsumsi, perilaku sosial dan mempengaruhi pilihan konsumen serta menjadi salah satu faktor utama yang harus dipertimbangkan dalam mempromosikan suatu produk (Rahman, Asrarhaghighi, \& Rahman, 2015). Hal ini memunculkan suatu tren di masyarakat yang dikenal dengan hijrah (berpindah / berubah). Tren hijrah menjadikan standar halal berkembang dari sekadar untuk produk makanan-minuman, kini menjamah produk jasa dan gaya hidup. Kosmetik saat ini dikategorikan sebagai produk gaya hidup (Bachdar, 2018). Pasar di Asia, khususnya Indonesia dan Malaysia, telah melihat lonjakan minat pada kosmetik halal. Pasar kosmetik halal pada Tahun 2023 diperkirakan akan meningkat sebesar $6.9 \%$ (US\$ 90 Miliar) dari Tahun 2017 (US\$ 61 Miliar). Indonesia merupakan negara kedua setelah India (US\$ 5.4 Miliar) yang diperkirakan akan mengalami peningkatan permintaan terhadap kosmetik halal sebesar US\$ 3.9 Miliar (Thomson, 2018). Produsen kosmetik berlomba menawarkan produk kosmetik dengan menggunakan bahanbahan dan proses yang tersertifikasi halal. PT
Paragon Innovation and Technology meluncurkan kembali kosmetik halal merek Make Over, sebelumnya kosmetik halal merek Wardah.

TINJAUAN

TEORI

DAN

\section{PENGEMBANGAN HIPOTESIS}

\section{Agama Islam terhadap Sikap Konsumen}

Menurut Al-Otoum \& Nimri, (2015); Essoo \& Dibb (2004), agama bertindak sebagai dasar di mana orang membangun keyakinan, sikap dan perilaku mereka. Dalam hukum Islam, ada hukum yang mempengaruhi perilaku konsumsi Muslim seperti yang diatur dalam Alquran dan hadis. Oleh karena itu, religiusitas memiliki pengaruh secara positif terhadap sikap konsumen pada produk kosmetik yang halal (Balques, Noer, \& Nuzulfah, 2017; Larasati, Hati, \& Safira, 2018; Rahman et al., 2015).

Individu dengan religius intrinsik menganggap bahwa agama merupakan fokus utama dalam kehidupan (Essoo \& Dibb, 2004). Selain itu menurut Ahmad, Rahman, \& Rahman (2015), bahwa Konsumen yang semakin religius seharusnya akan semakin memperhatikan kehalalan suatu produk 
termasuk kosmetik. Beberapa faktor akan mempengaruhi konsumen ketika konsumen memutuskan apakah akan menggunakan atau tidak. Sehingga muncul hipotesis sebagai berikut:

H1: Terdapat pengaruh positif dan signifikan antara Agama Islam terhadap sikap konsumen.

\section{Agama Islam terhadap Niat Beli}

Konsumen Muslim dengan tingkat religiusitas yang lebih tinggi biasanya memiliki niat yang lebih kuat untuk membeli produk halal, sehingga menghasilkan respons positif untuk mengkonsumsi produk halal (Adiba \& Wulandari, 2018). Religiusitas secara signifikan mempengaruhi niat seseorang dalam memilih produk halal (Balques et al., 2017; Mukhtar \& Butt, 2012; Sadra Tabassi, 2012).

Studi ini menyelidiki hubungan antara religiusitas dan sikap terhadap produk kosmetik, ketika konsumen menjadi lebih peduli dengan status halal dari produk yang mereka konsumsi. Sehingga muncul hipotesis sebagai berikut:

$\mathrm{H} 2$ : Terdapat pengaruh positif dan signifikan antara agama islam terhadap niat beli.
Pengetahuan Halal terhadap Sikap

\section{Konsumen}

Konsumen yang memiliki pengetahuan tentang suatu produk akan mempengaruhi mereka untuk menerima atau menolak penggunaan produk. Konsumen yang kurang pengetahuan tentang suatu produk cenderung menghindari membeli produk (Briliana \& Mursito, 2017). Pengetahuan memiliki pengaruh signifikan terhadap sikap konsumen terhadap kosmetik halal (Ahmad et al., 2015; Larasati et al., 2018; Rahman et al., 2015). Sikap ini memberikan informasi bahwa pasar memiliki potensi untuk produk baru dan karenanya pemasar dapat mengeksplorasi peluang dengan mengurangi disonansi ketidaktersediaan produk halal (Garg \& Joshi, 2018). Peningkatan permintaan kosmetik halal didorong oleh peningkatan pengetahuan dan informasi produk halal (Rahim, Zurina Shafii, \& Syahidawati Shahwan, 2015).

Sikap konsumen hanya didasarkan pada kepercayaan dan pengetahuan tentang barang atau komoditas tertentu di mana itu merupakan hasil dari proses pengumpulan informasi yang mempengaruhi tujuan individu untuk berperilaku dalam sikap tertentu (Putri, 
Daryanti, \& Ningtias, 2019). Hipotesis yang dapat diusulkan:

H3: Terdapat pengaruh positif dan signifikan antara pengetahuan halal terhadap sikap konsumen.

\section{Pengetahuan Halal terhadap Niat Beli}

Pengetahuan adalah hal yang penting bagi konsumen untuk memutuskan membeli suatu produk terutama produk yang halal (Maichum, Parichatnon, \& Peng, 2017). Konsumen yang lebih berpengetahuan tentang produk halal akan lebih berpotensi melakukan pembelian pada produk halal (Rahim et al., 2015). Pelanggan bersedia membayar lebih untuk mendapatkan produk halal karena mereka percaya diri dengan prinsip-prinsip Islam yang mempromosikan produk yang bersih, aman dan berkualitas (Jaafar, Omar, Osman, \& Faisol, 2013). Sehingga hipotesis yang dapat diusulkan:

H4: Terdapat pengaruh positif dan signifikan antara pengetahuan halal terhadap niat beli

\section{Gaya Hidup Halal terhadap Niat Beli}

Gaya hidup mencerminkan masalah apa yang sebenarnya yang ada di dalam pikiran pelanggan yang berbaur dengan berbagai hal yang terkait dengan masalah emosi dan psikologis konsumen (Setiadi, 2010). Hasil penelitian Listyorini (2012), menyatakan bahwa gaya hidup yang terdiri dari faktor sosial, faktor domestik, faktor kesenangan, faktor referensi dan identitas secara signifikan mempengaruhi niat pembelian (Ekasari \& Hartono, 2015; Nora, Liza \& Minarti, 2016; Ulfa, Wulandari, \& Subagio, 2014). Oleh karena itu, dihipotesiskan bahwa:

H5: Terdapat pengaruh positif dan signifikan antara gaya hidup halal terhadap niat beli.

\section{Sikap Kosumen terhadap Niat Beli}

Ketika konsumen merasa senang atau suka membeli kosmetik halal, konsumen akan cenderung memiliki niat untuk membeli kosmetik halal lagi di masa depan (Endah, 2014). Tidak ada perbedaan yang signifikan antara sikap terhadap intensi membeli konsumen pada produk kosmetik halal yang menggunakan halal positioning (Wardah) dengan produk kosmetik halal yang menggunakan neutral positioning (Sariayu) (Larasati et al., 2018). Semakin positif sikap konsumen dalam memilih kosmetik halal, semakin positif perilaku konsumen dalam memutuskan untuk membeli kosmetik halal (Briliana \& Mursito, 2017; Lada, Harvey 
Tanakinjal, \& Amin, 2009; Larasati et al., 2018; Maichum et al., 2017; Mukhtar \& Butt, 2012; Rahman et al., 2015).

Keinginan konsumen Muslim untuk membeli produk berlabel halal dari supermarket di Inggris juga ditentukan oleh sikap positif konsumen secara langsung (Elseidi, 2018). Konsumen Muslim sadar akan pentingnya membeli produk dengan label halal dan itu akan membuat niat yang lebih besar untuk membeli produk-produk tersebut. Sehingga hipotesis penelitan ini adalah:

H6: Terdapat pengaruh positif dan signifikan antara sikap konsumen terhadap niat beli.

Agama Islam terhadap Niat Beli dimediasi

\section{Sikap Konsumen}

Sikap memiliki efek mediasi yang signifikan terhadap niat pembelian untuk religiusitas (Briliana \& Mursito, 2017; Garg \& Joshi, 2018; Rahman et al., 2015). Pada penelitian Souiden \& Marzouki (2017), menunjukkan religiusitas memiliki pengaruh tidak langsung terhadap niat beli dengan sikap sebagai mediator. Semakin meningkat religiusitas konsumen maka akan semakin banyak pengetahuan dan informasi mereka tentang produk halal sehingga berdampak pada meningkatnya permintaan konsumen terhadap kosmetik halal (Hashim \& Musa, 2014). Sehingga muncul hipotesis sebagai berikut:

H7: Terdapat pengaruh positif dan signifikan antara agama islam terhadap niat beli dimediasi oleh sikap konsumen.

Pengetahuan Halal terhadap Niat Beli dimediasi Sikap Konsumen

Pengetahuan memiliki pengaruh terhadap intensi melalui sikap. Oleh karena itu, dengan meningkatkan pengetahuan akan cenderung mempengaruhi intensi konsumen untuk membeli suatu produk (Bang, Ellinger, Hadjimarcou, \& Traichal, 2000; Mukhtar \& Butt, 2012). Pengetahuan secara tidak langsung dipengaruhi oleh sikap konsumen karena semakin tinggi pengetahuan seseorang, semakin selektif dirinya dalam mengambil keputusan. Sehingga muncul hipotesis sebagai berikut:

H8: Terdapat pengaruh positif dan signifikan antara pengetahuan halal terhadap niat beli dimediasi oleh sikap.

Penelitian ini menganalisis dan membahas pengaruh langsung variabel agama Islam, pengetahuan halal, gaya hidup halal terhadap sikap konsumen dan niat beli 


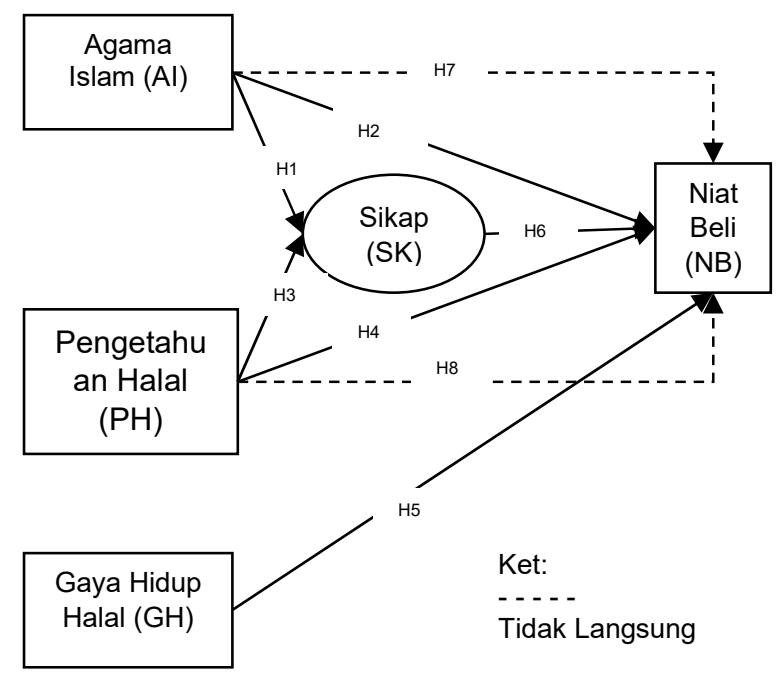

Gambar 1. Model Penelitian

kosmetik halal serta menganalisis pengaruh tidak langsung antara agama Islam, pengetahuan halal, gaya hidup halal terhadap niat beli kosmetik halal melalui sikap konsumen.

\section{METODE RISET}

Menurut Sekaran (2017), ukuran sampel dianggap representatif untuk digunakan adalah sedikitnya 5 atau tidak lebih dari 10 dikalikan jumlah indikator atau minimal 100 responden. Pada penelitian ini, ada 32 indikator dari seluruh variabel, maka akan dikalikan 5 atau 10 sehingga didapat responden sejumlah 160 atau 320 responden. Pengambilan sampel dalam penelitian ini adalah nonprobability sampling (pengambilan sampel secara tak acak) dengan teknik pengambilan purposive sampling. Sampel pada penelitian ini adalah Generasi Muslimah (Gen M) dan follower Instagram Official Make Over Indonesia (@makeoverid).

Data primer melalui instrumen kuesioner online dengan skala likert 1-5. Sedangkan data sekunder diperoleh dari literatur seperti buku, website, surat kabar, jurnal dan informasi yang terkait dengan topik penelitian. Kuisioner yang direspon berjumlah 211 respon. Tetapi ada sebanyak 26 kuisioner yang tidak memenuhi kriteria dalam penelitian. Sehingga kuisioner yang layak untuk dilakukan pengolahan data ada sebanyak 185 kuisioner. Data dianalisis secara kuantitatif menggunakan Smart PLS 3. Pengujian efek Mediasi menggunakan metode variance accounted for (VAF), yaitu:

$$
V A P=\frac{\text { Indirect } \text { Effect }}{\text { Diract Iffect + Indirect } \text { Iffect }}
$$

Jika nilai VAF di atas $80 \%$, maka menujukkan peran variabel mediasi sebagai mediasi penuh (full mediation). Variabel mediasi dikategorikan sebagai mediasi parsial apabila nilai VAF berkisar antara 20\% sampai dengan $80 \%$, namun jika nilai VAF kurang dari $20 \%$ dapat disimpulkan bahwa hampir tidak ada efek mediasi. 
Tabel 1. Path Coefficient \& Hipotesis

\begin{tabular}{|c|c|c|c|}
\hline & $\begin{array}{c}T \\
\text { Statistics } \\
\end{array}$ & $\begin{array}{c}P \\
\text { Values }\end{array}$ & Hipotesis \\
\hline $\mathrm{AI}$-> SK & 7.441 & 0.000 & $\begin{array}{c}\mathrm{H} 1 \\
\text { diterima }\end{array}$ \\
\hline $\mathrm{AI}->\mathrm{NB}$ & 2.147 & 0.032 & $\begin{array}{c}\mathrm{H} 2 \\
\text { diterima }\end{array}$ \\
\hline PH -> SK & 4.297 & 0.000 & $\begin{array}{c}\mathrm{H} 3 \\
\text { diterima }\end{array}$ \\
\hline $\mathrm{PH}->\mathrm{NB}$ & 3.089 & 0.002 & $\begin{array}{c}\mathrm{H} 4 \\
\text { diterima }\end{array}$ \\
\hline GH $->$ NB & 3.545 & 0.000 & $\begin{array}{c}\mathrm{H} 5 \\
\text { diterima }\end{array}$ \\
\hline SK -> NB & 4.178 & 0.000 & $\begin{array}{c}\mathrm{H6} \\
\text { diterima }\end{array}$ \\
\hline
\end{tabular}

HASIL

PENELITIAN

DAN

\section{PEMBAHASAN}

Pengujian hipotesis dapat dilakukan dengan menggunakan bootstrapping pada SMART PLS 3.0. Apakah hipotesis diterima atau ditolak dapat dilakukan dengan melihat nilai probabilitas dan T-Statistik. Hipotesis akan diterima apabila nilai $\mathrm{T}$-Statistik $>\mathrm{T}$ Tabel (1.96) dan $\mathrm{P}$ Values $<0.05$. Dapat dilihat pada Tabel 1.

Berdasarkan Tabel 1 di atas dapat disimpulkan bahwa hipotesis 1 yaitu agama Islam berpengaruh positif dan signifikan terhadap sikap konsumen. Hasil pengujian yang telah dilakukan menyatakan bahwa nilai T-Statistik $(7,441)>$ T-Tabel $(1,96)$ dan $P$ Values $(0,000)<0,05$ maka hipotesis 1 diterima. Hal ini sejalan dengan penelitian yang dilakukan Balques et al. (2017); Larasati 114 et al. (2018); Rahman et al. (2015), bahwa Semakin baik dan meningkat agama seseorang maka akan semakin membentuk sikap positif konsumen pada produk kosmetik halal. Responden penelitian yang merupakan Generasi Muslimah menyadari pentingnya produk halal karena mereka beranggapan aktivitas konsumsi produk halal (kosmetik halal) merupakan bagian dari ibadah. Sehingga sikap mereka mulai tanggap dan melakukan pencarian dan evaluasi informasi mengenai produk kosmetik halal, salah satunya kosmetik halal Make Over.

Hasil pengujian hipotesis 2 yaitu agama Islam berpengaruh positif dan signifikan terhadap niat beli. Karena nilai $\mathrm{T}$ Statistik $(2,147)>$ T Tabel $(1,96)$ dan P Values $(0,032)$ $<0,05$ sehingga hipotesis 2 diterima. Sesuai dengan penelitian yang dilakukan Adiba \& Wulandari, (2018); Balques et al. (2017); Mukhtar \& Butt, (2012); Sadra Tabassi (2012), bahwa Muslim dengan tingkat religiusitas yang lebih tinggi biasanya memiliki niat yang lebih kuat untuk membeli produk halal, sehingga menghasilkan respon positif untuk mengkonsumsinya. Peningkatan religiusitas Generasi Muslimah yang merupakan follower Instagram (IG) official Make Over 
(@makeoverid) menjadi pemicu niat beli kosmetik halal Make Over. Generasi Muslimah mengakui bahwa kewajiban dalam agama adalah perhatian utama saat membeli kosmetik halal.

Berdasarkan uji hipotesis 3 yaitu pengetahuan halal berpengaruh positif dan signifikan terhadap sikap konsumen. Karena nilai T Statistik $(4,297)>\mathrm{T}$ Tabel $(1,96)$ dan $\mathrm{P}$ Values $(0,000)<0,050$ maka hipotesis 3 diterima. Sejalan dengan penelitian Ahmad et al., (2015); Larasati et al., (2018); Rahman et al. (2015), bahwa konsumen yang memiliki pengetahuan tentang suatu produk akan mempengaruhi mereka untuk menerima atau menolak penggunaan produk. Generasi Muslimah memiliki pengetahuan untuk membedakan produk yang diperbolehkan dan dilarang Islam. Mereka bisa melihat dan mencari beberapa informasi yang tertera pada kemasan produk. Menggali informasi detail apakah terjamin aman atau tidaknya produk kosmetik halal Make Over.

Hasil hipotesis 4 menyatakan bahwa pengetahuan halal berpengaruh positif dan signifikan terhadap niat beli. Karena nilai $\mathrm{T}$ Statistik $(3,089)>$ T Tabel $(1,96)$ dan P Values
$(0,000)<0,050$ sehingga hipotesis 4 diterima. Sejalan dengan penelitian yang dilakukan oleh Jaafar et al. (2013); Rahim et al. (2015), bahwa konsumen yang lebih berpengetahuan tentang produk halal akan lebih berpotensi melakukan pembelian pada produk halal. Banyaknya pengetahuan yang telah didapat Generasi Muslimah akan menjadi sebuah tindakan atau niat untuk membeli kosmetik halal. Pertimbangan seperti kehalalan kosmetik, formula yang cocok di kulit, pilihan warna, bisa menjadi alasan timbulnya niat beli Generasi Muslimah terhadap kosmetik halal Make Over. Selain itu adanya pengaruh informasi dari internet, keluarga atau orang terdekat dapat mempengaruhi mereka untuk memiliki niat beli kosmetik Make Over.

Hasil hipotesis 5 ditemukan bahwa gaya hidup halal berpengaruh positif dan signifikan terhadap niat beli. Di mana nilai $\mathrm{T}$ Statistik $(3,545)>$ T Tabel $(1,96)$ dan P Values $(0,000)$ $<0,050$ sehingga hipotesis 5 diterima. Sesuai dengan penelitian yang dilakukan oleh Ekasari \& Hartono (2015); Nora, Liza \& Minarti (2016); Ulfa et al. (2014), menyatakan bahwa gaya hidup berdampak positif dan signifikan terhadap niat pembelian. Kosmetik saat ini 
yang termasuk ke dalam kategori gaya hidup, mempengaruhi Generasi Muslimah mengikuti perkembangan inovasi kosmetik. Mereka berupaya menerapkan nilai-nilai agama ke segala aspek kehidupan, termasuk dalam hal pemilihan kosmetik halal. Sekarang ini, semakin banyak konsumen yang memutuskan untuk membeli suatu produk dengan memerhatikan nilai-nilai atau sisi agama (Burhanudin, 2018). Terlebih lagi konsumen yang berada di kelas menengah, sangat suka gaya hidup yang experience, sehingga dapat membentuk market yang luar biasa. Jika ada demand maka supply akan merespon hal tersebut (Kementrian Keuangan, 2019).

Hasil hipotesis 6 ditemukan bahwa sikap berpengaruh positif dan signifikan terhadap niat beli. Diketahui nilai T Statistik $(4,178)>$ T Tabel $(1,96)$ dan P Values $(0,000)$ $<0,050$ sehingga hipotesis 6 diterima. Sejalan dengan penelitian yang dilakukan oleh Elseidi (2018); Lada, Harvey Tanakinjal, \& Amin (2009); Mukhtar \& Butt (2012); Rahman et al. (2015), bahwa semakin positif sikap konsumen dalam memilih kosmetik halal, semakin positif perilaku konsumen dalam memutuskan untuk membeli kosmetik halal (Briliana \& Mursito, 2017; Larasati et al., 2018; Maichum et al.,
2017). Sikap konsumen yang positif dengan sadar, peduli dan melakukan evaluasi dengan mencari tahu informasi mengenai kehalalan produk kosmetik halal. Hasil dari pengumpulan informasi tersebut menghasilkan sikap positif yang direspon baik oleh produsen kosmetik. Salah satunya perusahaan Paragon yang mengeluarkan berbagai jenis merek kosmetik halal (Wardah, Make Over \& Emina). Sehingga Masyarakat menyukai dan memilih kosmetik halal Make Over dengan segala kualitas dan manfaat yang ditawarkan.

Pengujian efek mediasi yaitu uji pengaruh tidak langsung variabel eksogen (agama Islam dan pengetahuan halal) dengan variabel endogen (niat beli) melalui mediasi variabel sikap dapat dilihat pada Tabel 2.

Berdasarkan Tabel 2, pada hasil uji hipotesis 7 terdapat efek mediasi variabel sikap antara hubungan agama Islam terhadap nait beli. Karena hasil uji pengaruh langsung pada hipotesis 2 diterima sehingga hipotesis 7 dapat dilakukan uji efek mediasi. Hasil uji efek mediasi ditemukan bahwa nilai Variance Accounted For (VAF) yaitu sebesar $48 \%$. Artinya jenis efek mediasi variabel sikap adalah mediasi sebagian (partial mediation). 
$\frac{\text { Tabel 2. Specific Indirect Effect \& Hipotesis }}{T}$

\begin{tabular}{|c|c|c|c|}
\hline & $\begin{array}{c}T \\
\text { Statistics }\end{array}$ & $\begin{array}{c}P \\
\text { Values }\end{array}$ & Hipotesis \\
\hline $\begin{array}{l}\mathrm{AI}->\mathrm{SK} \\
->\mathrm{NB}\end{array}$ & 3.742 & 0.000 & $\begin{array}{c}\mathrm{H} 7 \\
\text { diterima }\end{array}$ \\
\hline $\begin{array}{l}\mathrm{PH}->\mathrm{SK} \\
->\mathrm{NB}\end{array}$ & 2.841 & 0.005 & $\begin{array}{c}\mathrm{H} 8 \\
\text { diterima }\end{array}$ \\
\hline
\end{tabular}

Sejalan dengan penelitian Briliana \& Mursito (2017); Garg \& Joshi (2018); Rahman et al.

(2015); Souiden \& Marzouki (2017), Peningkatan religiusitas akan semakin kuat melalui sikap konsumen bahwa pentingnya menggunakan produk kosmetik halal. Religiusitas mempengaruhi orientasi mereka mengenai pola konsumsi, perilaku sosial dan mempengaruhi sikap Generasi Muslimah dalam memilih produk kosmetik halal. Adanya sikap positif Generasi Muslimah terhadap kosmetik halal memicu timbulnya niat untuk membeli produk kosmetik halal Make Over.

Hasil uji hipotesis 8, terdapat efek mediasi variabel sikap antara hubungan pengetahuan halal terhadap niat beli. Karena hasil uji pengaruh langsung pada hipotesis 4 diterima sehingga hipotesis 8 dapat dilakukan uji efek mediasi. Hasil uji efek mediasi ditemukan bahwa nilai Variance Accounted For (VAF) yang diperoleh yaitu $33 \%$. Artinya jenis efek mediasi variabel sikap adalah mediasi sebagian (partial mediation). Sejalan dengan penelitian yang dilakukan Bang et al. (2000); Mukhtar \& Butt (2012), bahwa semakin tinggi pengetahuan seseorang, semakin selektif dirinya dalam memilih produk yang akan digunakan. Meningkatnya pengetahuan halal follower Make Over Generasi Muslimah akan semakin meningkat juga niat beli kosmetik halal Make Over. Peningkatan tersebut diperkuat melalui sikap atau kesadaran konsumen mengenai pentingnya menggunakan produk kosmetik halal yang aman dan berkualitas. Mereka mendapatkan banyak pengetahuan dari berbagai sumber informasi, seperti media cetak, elektronik maupun internet (website / sosial media). Sehingga informasi tersebut dapat mempengaruhi sikap Generasi Muslimah dalam memilih produk kosmetik halal Make Over.

\section{KESIMPULAN DAN SARAN}

Berdasarkan hasil penelitian, maka dapat diambil kesimpulan bahwa Responden penelitian yang berjumlah 185 responden merupakan konsumen kosmetik halal Make Over dan follower instagram official Make Over (@Makeoverid)._Mereka adalah 
Muslimah yang dominan berumur 25-29

Tahun dengan jumlah 109 responden (58,92\%). Pendidikan terakhir adalah Sarjana atau S1 sebesar 129 responden $(69,73 \%)$. Status pekerjaan responden adalah Karyawan Swasta dengan jumlah 99 responden $(53,51 \%)$. Rentang penerimaan responden berkisar antara Rp.2.600.000 - Rp.5.200.000 perbulan dengan jumlah 114 responden (61,62\%). Mereka juga memperoleh informasi mengenai merek dan kehalalan produk kosmetik Make Over dari Teman.

Agama Islam berpengaruh positif dan signifikan terhadap sikap konsumen. Konsumen yang memiliki religiusitas yang tinggi maka akan semakin positif sikap mereka untuk lebih peduli dengan kosmetik halal. Karena kosmetik yang digunakan nantinya akan menyerap ke dalam kulit. Sehingga mereka memilih untuk menggunakan kosmetik halal.

Agama Islam berpengaruh positif dan signifikan terhadap niat beli. Kosumen secara langsung akan memilih kosmetik halal Make Over karena pengaruh dari religiusitas atau agama yang dianut konsumen yaitu Islam. Karena dalam Islam mengaruskan setiap muslim mengonsumsi produk halal.
Pengetahuan halal berpengaruh positif dan signifikan terhadap sikap konsumen. Kosumen penelitian ini merupakan Generasi Muslimah modern yang tanggap terhadap perubahan. Mereka juga melek terhadap perkembangan pengetahuan dan paham akan ajaran agama. Meningkatnya pengetahuan halal konsumen mengenai kosmetik halal akan menimbulkan sikap positif (peduli dan sadar) mengenai kewajiban, manfaat dan pengaruh penggunaan kosmetik halal bagi kehidupan mereka kedepannya. Karena halal dapat membawa berkah untuk kehidupan.

Pengetahuan halal berpengaruh positif dan signifikan terhadap niat beli.. Make Over sebagai kosmetik halal dapat memberikan kepercayaan bahwa kosmetik tersebut aman digunakan, sehingga konsumen tidak khawatir saat menjalankan ibadah dan dapat menunjang penampilan mereka untuk riasan yang natural atau matte. Informasi mengenai kehalalan Make Over menambah referensi konsumen untuk kosmetik halal dan memicu niat beli mereka pada kosmetik Make Over.

Gaya hidup halal berpengaruh positif dan signifikan dengan niat beli. Kosmetik merupakan produk gaya hidup yang dapat menonjolkan prestige dari penggunannya. 
Make Over sebagai kosmetik dengan kualitas premium, ditawarkan dengan harga yang relatif mahal dibanding pesaing satu produsennya (Wardah dan Emina). Hal tersebut menjadi salah satu faktor yang mempengaruhi niat beli konsumen terhadap kosmetik halal Make Over. Karena pada penelitian ini, konsumen Make Over adalah golongan kelas menengah atas yang bersifat konsumtif.

Sikap konsumen berpengaruh positif dan signifikan terhadap niat beli. Sikap konsumen yang positif (peduli dan sadar) dengan kosmetik halal direspon oleh produsen kosmetik. Salah satunya perusahaan Paragon yang mengeluarkan berbagai jenis merek kosmetik halal. Kemudian sikap positif tadi memunculkan tren hijrah, halal market dan kosmetik halal di kalangan masyarakat Indonesia. Hal ini untuk memenuhi permintaan dari konsumen Generasi Muslimah terhadap niat beli produk halal.

Selanjutnya agama Islam berpengaruh positif dan signifikan terhadap niat beli dimediasi sikap konsumen. Keyakinan pada agama mempengaruhi semua urusan mereka dalam hidup. Ajaran agama Islam mengenai kehalalan suatu produk mengubah pandangan konsumen Generasi Muslimah saat memilih kosmetik. Mereka harus mengambil sikap untuk memilih kosmetik halal agar tidak bertentangan dengan ajaran agama Islam. Oleh karena itu timbulnya niat untuk membeli produk kosmetik halal Make Over.

Pengetahuan halal berpengaruh positif dan signifikan terhadap niat beli dimediasi sikap konsumen. Pada penelitian ini konsumen dominan memperoleh pengetahuan mengenai kehalalan Make Over dari teman. Hal ini menunjukkan bahwa pengetahuan halal yang didapat konsumen mempengaruhi sikap mereka dengan mengevaluasi secara positif pengalaman teman-teman, informasi media sosial dan iklan sehingga hasil evaluasi ini memunculkan niat beli pada kosmetik halal Make Over.

Adapun beberapa saran terkait penelitian ini agar dapat menjadi masukan bagi pengembangan penelitian ini di masa yang akan datang adalah sebagai berikut:

1. Peneliti dapat menganalisis lebih lanjut pada responden non muslim di daerah tertentu atau pengunjung outlet kosmetik halal agar bisa membandingkan bagaimana 
pengaruh lainnya dengan purchase

intention.

2. Memperluas analisis hubungan pengaruh antara variabel eksogen dan endogen lain dengan menggunakan mediasi selain dari penelitian ini. Seperti pengaruh islamic branding / religiosity terhadap lifestyle, repurchase intention, purchase decision dan loyalitas.

3. Kedepannya dapat menggunakan aplikasi kuisioner gratis atau berbayar lain yang lebih menarik dan logis. Sehingga responden tidak bosan mengisi kuisioner dan peneliti bisa langsung mendapatkan responden sesuai dengan kriteria penelitian dan layak untuk dilakukan pengolahan data. 
Analisis Perilaku Islami Terhadap Niat Beli Kosmetik Halal........ (Lisa Adriani \& Ma'ruf)

\section{DAFTAR PUSTAKA}

Adiba, E. M., \& Wulandari, D. A. (2018). Pengaruh Halal Knowledge, Islamic Religiosity, dan Attitude terhadap Behavior Konsumen Muslim Generasi Y Pengguna Kosmetik Halal di Surabaya. INOBIS: Jurnal Inovasi Bisnis Dan Manajemen Indonesia, 1(3), 357-369.

Ahmad, A. N., Rahman, A. A., \& Rahman, S. A. (2015). Assessing Knowledge and Religiosity on Consumer Behavior towards Halal Food and Cosmetic Products. International Journal of Social Science and Humanity, 5(1), 10-14.

Al-Otoum, F. J., \& Nimri, R. S. (2015). Antecedents of Consumers' Behavior towards Halal Food among Jordanian Customers: A Structural Equation Modeling ( SEM ) Approach. Journal of Marketing and Consumer Research, 12, 19-26.

Aziz, \& Chok. (2013). The Role of Halal Awareness, Halal Certification, and Marketing Components in Determining Halal Purchase Intention Among Non-Muslims in Malaysia: A Structural Equation Modeling Approach. Journal of International Food and Agribusiness Marketing, 25(1), 1-23.

Bachdar, S. (2018). Mengenal Paragon, Produsen di Balik Kemahsyuran Wardah. Retrieved from Markeeters website: http://marketeers.com/mengenal-paragon-produsen-di-balik-kemahsyuranwardah

Balques, A., Noer, B. A., \& Nuzulfah, V. (2017). Analisis Sikap, Norma Subjektif, Dan Niat Beli Produk Kosmetik Halal Pada Konsumen Muslimah Di Surabaya. Jurnal Sains Dan Seni ITS, 6(2).

Bang, H. K., Ellinger, A. E., Hadjimarcou, J., \& Traichal, P. A. (2000). Consumer concern, knowledge, belief, and attitude toward renewable energy: An application of the reasoned action theory. Psychology and Marketing, 17(6), 449-468.

Briliana, V., \& Mursito, N. (2017). Exploring antecedents and consequences of Indonesian Muslim youths' attitude towards halal cosmetic products: A case study in Jakarta. Asia Pacific Management Review, 22(4), 176-184.

Burhanudin, T. (2018). Makin Kaya, Makin Religius, dan Kian Konsumtif. Retrieved from Marketing.co.id website: https://marketing.co.id/makin-kaya-makin-religius-dan-kian-konsumtif/ 
Ekasari, N., \& Hartono, R. (2015). Pengaruh Faktor-Faktor Gaya Hidup Konsumen Terhadap Keputusan Pembelian Laptop Apple. Jurusan Manajemen Fakultas Ekonomi Dan Bisnis Universitas Jambi, 1(1), 65-72.

Elseidi, R. I. (2018). Determinants of halal purchasing intentions: evidences from UK. Journal of Islamic Marketing, 9(1), 167-190.

Endah, N. H. (2014). Consumers's purchasing behavior toward halal labeled cosmetics in Indonesia. Jurnal Ekonomi Dan Pembangunan, 22(1), 11-25.

Essoo, N., \& Dibb, S. (2004). Religious Influences on Shopping Behaviour: An Exploratory Study. Journal of Marketing Management, 20(7-8), 683-712.

Garg, P., \& Joshi, R. (2018). Purchase intention of "Halal" brands in India: the mediating effect of attitude. Journal of Islamic Marketing, 9(3), 683-694.

Hashim, A. J. bt C. M., \& Musa, R. (2014). Factors influencing Attitude towards halal cosmetic among young adult urban Muslim Women: A focus group analysis. Procedia - Social and Behavioral Sciences, 130, 129-134.

Jaafar, H. S., Omar, E. N., Osman, M. R., \& Faisol, N. (2013). The Concept of Halal Logistics - an. 5th International Conference on Transport and Logistics (ICLT 2013), (January 2014), 2006-2011.

Kementrian Keuangan. (2019). Kelas Menengah Penggerak Ekonomi Indonesia. Retrieved from Kementrian Keuangan website: https://www.kemenkeu.go.id/publikasi/berita/kelas-menengahpenggerak-ekonomi-indonesia/

Lada, S., Harvey Tanakinjal, G., \& Amin, H. (2009). Predicting intention to choose halal products using theory of reasoned action. International Journal of Islamic and Middle Eastern Finance and Management, 2(1), 66-76.

Larasati, A., Hati, S. R. H., \& Safira, A. (2018). Religiusitas dan pengetahuan terhadap sikap dan intensi konsumen Muslim untuk membeli produk kosmetik halal. Esensi: Jurnal Bisnis Dan Manajemen, $8(2), 105-114$. 
Listyorini, S. (2012). Analisis Faktor-Faktor Gaya Hidup dan Pengaruhnya Terhadap Pembelian Rumah Sehat Sederhana (Studi Pada Pelanggan Perumahan Puri Dinar Mas PT. Ajisaka di Semarang). Jurnal Administrasi Bisnis Undip, 1(1), 12-24.

Maichum, K., Parichatnon, S., \& Peng, K.-C. (2017). The Influence of Attitude, Knowledge and Quality on Purchase Intention towards Halal Food: A Case Study of Young Non-Muslim Consumers in Thailand. IRA-International Journal of Management \& Social Sciences (ISSN 2455-2267), 6(3), 354.

Mukhtar, A., \& Butt, M. M. (2012). Intention to choose Halal products: The role of religiosity. Journal of Islamic Marketing, 3(2), 108-120.

Nora, Liza \& Minarti, N. S. (2016). The Role of Religiosity, Lifestyle, Attitude as Determinant Purchase Intention. The 2nd International Multidisciplinary Conference 2016, (October 2016), $135-148$.

Putri, I. S., Daryanti, S., \& Ningtias, A. R. (2019). The influence of knowledge and religiosity with mediation of attitude toward the intention of repurchasing halal cosmetics. Proceedings of the 12th Advances in Economics, Business and Management Research, 72(ICMBR 2018), 172-177.

Rahim, N. F., Zurina Shafii, \& Syahidawati Shahwan. (2015). Awareness and perception of Muslim consumers on halal cosmetics and personal care products. International Journal of Business, Economics and Management, 2(1), 1-14.

Rahman, A. A., Asrarhaghighi, E., \& Rahman, S. A. (2015). Consumers and halal cosmetic products: Knowledge, religiosity, attitude and intention. Journal of Islamic Marketing, 6(1), 148-163.

Sadra Tabassi. (2012). The role of animosity, religiosity and ethnocentrism on consumer purchase intention: A study in Malaysia toward European brands. African Journal of Business Management, 6(23), 6890-6902.

Sekaran, U. (2017). Metode Penelitian untuk Bisnis (6th ed.). Jakarta: Salemba Empat.

Setiadi, N. . (2010). Perilaku Konsumen (Revisi). Jakarta: Kencana Prenada Media Group. 
Souiden, N., \& Marzouki, R. (2017). Consumer attitudes and purchase intentions toward Islamic banks: the influence of religiosity. International Journal of Bank Marketing, 33(2), 1-37.

Thomson, R. (2018). State of the Global Islamic Economy Report 2018/19. In Dubai International Financial Centre. Retrieved from https://haladinar.io/hdn/doc/report2018.pdf

Ulfa, R., Wulandari, D., \& Subagio, N. A. (2014). Pengaruh Hijabers Community Terhadap Gaya Hidup Dan Keputusan Pembelian Hijab Pada Mahasiswa Fakultas Ekonomi Universitas Jember ( The Influence of Hijabers Community through Lifestyle and Hijab Purchase Decision in Students ' of Faculty of Economics Univ. E-Journal Ekonomi Bisnis Dan Akuntansi Universitas Jember, 1(1), $67-71$. 